\title{
Mitochondrial Dynamics: In Cell Reprogramming as It Is in Cancer
}

\author{
Javier Prieto $^{1}$ and Josema Torres ${ }^{1,2}$ \\ ${ }^{1}$ Departamento Biología Celular, Biología Funcional y Antropología Física, University of Valencia, 46100 Burjassot, Spain \\ ${ }^{2}$ Instituto de Investigación Sanitaria (INCLIVA), 46010 Valencia, Spain
}

Correspondence should be addressed to Josema Torres; josema.torres@uv.es

Received 13 January 2017; Accepted 19 March 2017; Published 18 April 2017

Academic Editor: Riikka Hämäläinen

Copyright (c) 2017 Javier Prieto and Josema Torres. This is an open access article distributed under the Creative Commons Attribution License, which permits unrestricted use, distribution, and reproduction in any medium, provided the original work is properly cited.

\begin{abstract}
Somatic cells can be reprogrammed into a pluripotent cellular state similar to that of embryonic stem cells. Given the significant physiological differences between the somatic and pluripotent cells, cell reprogramming is associated with a profound reorganization of the somatic phenotype at all levels. The remodeling of mitochondrial morphology is one of these dramatic changes that somatic cells have to undertake during cell reprogramming. Somatic cells transform their tubular and interconnected mitochondrial network to the fragmented and isolated organelles found in pluripotent stem cells early during cell reprogramming. Accordingly, mitochondrial fission, the process whereby the mitochondria divide, plays an important role in the cell reprogramming process. Here, we present an overview of the importance of mitochondrial fission in both cell reprogramming and cellular transformation.
\end{abstract}

\section{Introduction}

Mitochondria and their movement as organelles were described for the first time 100 years ago [1]. In addition to producing energy by oxidative phosphorylation (OXPHOS) of pyruvate and beta-oxidation of lipids, the mitochondria play important roles in the regulation of a wide variety of intracellular processes, such intracellular calcium homeostasis [2], iron-sulfur protein assemblage [3], or apoptosis [4] and innate immunity cell signaling pathways [5].

There is no de novo mitochondrial biogenesis; the mitochondria divide by fission and join by fusion $[6,7]$. Fission-fusion balance allows the mitochondria to acquire different structures. When fission is higher than fusion, mitochondria become fragmented and isolated. When fusion is higher than fission, these organelles display a tubular and networked morphology. Cells can shift the fission/fusion balance in response to either intracellular or extracellular stimuli. And thus, mitochondrial fission is increased during (1) G2/M phase of cell cycle, to guarantee an accurate mitochondrial segregation between the two daughter cells during cell division $[8,9]$; (2) mitochondrial transport in neurons, to facilitate their transport along the axons and dendrites [10]; (3) early phase of apoptosis, to facilitate cytochrome $\mathrm{c}$ release into the cytoplasm by inducing mitochondrial cristae remodeling [11, 12]; or (4) mitophagy, to eliminate dysfunctional mitochondria [13]. On the other hand, mitochondrial fusion is favored during (1) G1/S transition of cell cycle, to provide with the necessary energy for DNA synthesis [14]; (2) cell survival during starvation, to maximize energy production and protect themselves against mitophagy [15, 16]; (3) mitochondrial complementation, to avert the loss of mitochondrial functions caused by damaged components of these organelles [17, 18]; or (4) embryonic development, as in trophoblast or placenta formation $[19,20]$. Regulation of mitochondrial dynamics is therefore crucial for the correct implementation of mitochondrial functions. In fact, mutations in the components that drive or regulate fusion and fission processes are associated with several human pathologies, such as optic atrophy (Opa1 gene) or Charcot-Marie-Tooth disease (MFN2 and GDAP1 genes) [18].

The molecular machinery that controls the fission and fusion processes includes proteins that are either localized in mitochondrial membranes or recruited to the surface of these organelles in response to different stimuli. Three key 
players of the fusion process are mitofusin (Mfn) 1 and 2 and optic atrophy protein 1 (Opa1), both of which are transmembrane proteins localized in the outer or inner mitochondrial membranes, respectively. Mfn1 and Mfn2 tether adjacent mitochondria by forming trans-hetero- or homocomplexes to promote the fusion of their outer membranes $[17,19]$. It has been suggested that a heptad repeat region in Mfn1 adopts an antiparallel coiled coil conformation to tether neighboring mitochondria during the fusion process [21]. Cells that lack both Mfn1 and Mfn2 display fragmented mitochondria and fail in mitochondrial complementation $[19,22]$, which eventually leads to an accumulation of dysfunctional mitochondria [17]. Fusion of outer and inner mitochondrial membranes is a temporally linked, multistep process controlled by transmembrane adaptor proteins that span both membranes [23]. Mfn1 and Mfn2 interact with Opa1 [24], suggesting that the interaction of Mfn1/2 with Opal and/or other adapters physically connects both membranes to coordinate the fusion of these organelles [25]. The fission process is executed by dynamin-related protein 1 (Drp1), a cytosolic protein with GTPase activity [26, 27]. Drp1 is activated in the cytosol by posttranslational modifications in response to different stimuli and then recruited to the mitochondrial surface by its interaction with protein adapters [28, 29]. Mitochondria-recruited Drp1 oligomerizes on the external surface of mitochondria forming a ring-shaped structure around the organelle. Once a Drp1 spiral around the mitochondria is completed, the hydrolysis of GTP bound to Drp1 causes a conformational change in the protein that causes the constriction of the ring, eventually leading to the fragmentation of mitochondria in two different organelles [30, 31]. Different protein adapters for Drp1 have been described, including mitochondrial fission protein 1 (Fis1) [28], mitochondrial fission factor (Mff) [32], and mitochondrial dynamic proteins of 49 (Mid49) and 51 (Mid51) $\mathrm{kDa}[33,34]$. Recent work has shown that these Drp1 adapters could either operate together or be redundant in the recruitment of the GTPase to the mitochondria $[35,36]$.

Mitochondrial dynamics, in terms of the fission/fusion balance, is a highly regulated process where posttranslational modifications play a central role in the outcome of this equilibrium. Phosphorylation Mfn1 by extracellular regulated kinase 1/2 (Erk1/2) impairs its oligomerization properties and leads to decreased mitochondrial fusion [37]. Also, phosphorylation of Mfn2 by c-Jun N-terminal kinase (Jnk) results in its ubiquitin-mediated proteasomal degradation, leading to increased mitochondrial fragmentation [38]. Opal undergoes proteolytic processing by several proteases to produce short and long protein isoforms [39-41]; however, it is poorly understood how this proteolytic processing alters mitochondrial dynamics [42]. It is known that alterations in Opal proteolysis affect inner mitochondrial membrane dynamics and cristae structure [43]. Drp1 is target of several posttranslational modifications that affect its function: phosphorylation, ubiquitination, sumoylation, and nitrosylation [7]. Regarding its phosphorylation, only the phosphorylation in three Drp1 residues by different kinases has been well documented to play a role in the regulation of this protein: serine 579 (serine 616 in humans), serine 600 (serine 637 in humans), and serine 656 (serine 693 in humans). Phosphorylation of any of these three residues affects Drp1 protein-protein interactions and can either impair or favor the mitochondrial recruitment of Drp1. It has been described that Ser579 phosphorylation induces mitochondrial fission [9, 44-48]; Ser656 phosphorylation induces mitochondrial fusion [49]; and Ser600 phosphorylation induces either mitochondrial fission [50,51] or fusion $[15,48,52-55]$, depending on the cellular context (Figure 1). Recently, it has been described that AMP-activated protein kinase (Ampk) induces mitochondrial fission in response to energy stress through direct phosphorylation of Mff [56].

Endoplasmic reticulum (ER) also plays an important role during mitochondrial fission. It has been shown that ER projections wrap mitochondria around the areas where fragmentation of these organelles takes place. These ERmitochondria contacts are not Drp1-dependent, but rather enhance the recruitment of the GTPase to these focal points [57, 58]. ER-associated inverted formin 2 (Inf2) plays an important role in mitochondrial fission by inducing the accumulation of actin filaments around the ERmitochondria contact points. The distribution of actin filaments around the mitochondria at the ER contact points may drive an initial mitochondrial constriction to favor the action of mitochondrion-bound Drp1 [58]. Also, a profission role for ganglioside-induced differentiationassociated protein 1 (Gdap1) has been proposed, as Gdap1 favors the formation of ER-mitochondria contacts in certain neural cell types and its overexpression leads to fragmented mitochondria [59-61].

\section{Mitochondrial Dynamics during Embryonic Development and Cell Differentiation}

As the oocyte provides all the mitochondria to the zygote during fecundation, all these organelles are of maternal origin. During the first phase of embryonic development, mitochondrial biogenesis and mtDNA synthesis are not active and mitochondrial mass decays by half upon each cell division [62]. During the early stages of development, cells have a simple mitochondrial network: cristae-poor and fragmented mitochondria with low mtDNA copy number. Conversely, the mitochondrial network of somatic cells shows a complex structure: cristae-rich and tubular mitochondria with a dense mitochondrial matrix and high mtDNA copy number [62-66].

Cell differentiation during embryogenesis leads to a progressive increase in mtDNA copy number, mitochondrial mass, size, and complexity of these organelles [67-69]. For instance, the specification of cardiomyocyte $[70,71]$ or adipocyte [72] cell lineages is characterized by an increase in the elongation, matrix complexity, and functionality of mitochondria. Also, during cardiomyocyte differentiation, the closure of the mitochondrial permeability transition pore increases mitochondrial membrane potential and reduces reactive oxygen species (ROS) levels [71]. Mfn2 and Opa1 play an important role in this mitochondrial maturation 


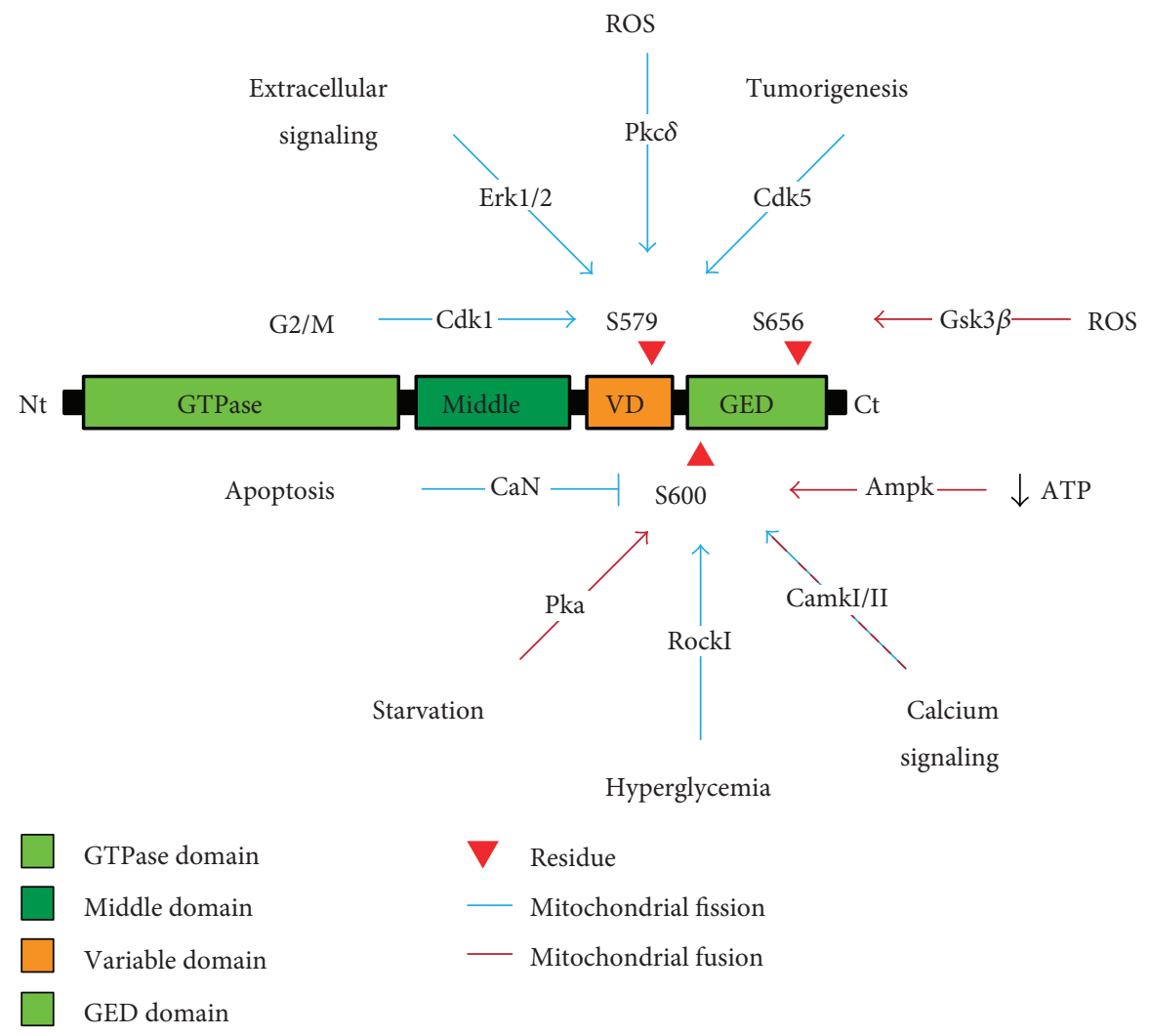

Figure 1: Drp1 regulation by phosphorylation. Phosphorylation of Ser579 by Cdk1 [9, 44], Pkc $\delta$ [45], Erk1/2 [46, 47], or Cdk5 [48] induces mitochondrial fission. Phosphorylation of Ser656 by Gsk3 $\beta$ [49] induces mitochondrial fusion. Phosphorylation of Ser600 by Pka [15, 52, 53], CamkII [48], or Ampk [55] induces mitochondrial fusion, and its dephosphorylation by calcineurin (CaN) [53, 54] induces mitochondrial fission, but, in some circumstances, phosphorylation of Ser600 by CamkI [50] or RockI [51] can induce mitochondrial fission.

process. Lack of $M f n 2$ or Opa1 prevents mitochondrial fusion leading to an increase in cytosolic calcium levels and calcineurin activation, which impairs efficient cardiomyocyte differentiation [73]. Mitochondrial integrity, in terms of energetics, $\mathrm{Ca}^{2+}$-storage/buffering, neurotransmitter metabolism, or ROS signaling, plays a central role in neuronal physiology during both development and adulthood [74]. Interestingly, a wide range of neurodegenerative diseases, such as Charcot-Marie-Tooth disease, Parkinson's disease, or several ataxias, are linked to mutations in geneencoding proteins involved in mitochondrial dynamics, underscoring the role of this equilibrium in maintaining neuronal homeostasis [75].

The low rate of mtDNA replication observed during the very early stages of embryonic development and in embryonic stem (ES) cells is associated with high methylation levels in the genes encoding DNA mitochondrial polymerase subunit gamma [76] and mitochondrial transcription factor A (Tfam) [77], which impairs their expression in cells of the early embryo. However, demethylation of these genes is induced upon implantation of the embryo, leading to an increase in their expression and mtDNA replication.

Despite the profound changes experimented by the mitochondrial network during cell differentiation, the regulation of mitochondrial dynamics in ES or adult stem cells is poorly understood. ES cells present a fragmented mitochondrial morphology $[65,78]$. Surprisingly, downregulation of growth factor erv1-like (Gfer) in ES cells, which leads to an increase in Drp1 protein levels and mitochondrial fission rates, impairs pluripotency and induces apoptosis [79]. On the other hand, adult neural stem (NS) cells display tubular mitochondrial morphology and NS cells derived from $M f n 1 / 2$ - or Opa1-null mice, which display increased mitochondrial fragmentation, show decreased self-renewal and a greater tendency to cell commitment associated with augmented ROS and Nfe2-related factor 2 (Nrf2) expression levels [80]. These evidences strongly suggest that a proper balance of mitochondrial fission and fusion is required to maintain a homogeneous and functional mitochondrial population in the cells.

\section{Mitochondrial Dynamics in Cell Reprogramming}

Somatic cells can be reprogrammed to a pluripotent state similar to that of ES cells by ectopic expression of Oct4, Sox2, Klf4, and c-Myc (OSKM hereinafter) [81]; chemical treatment [82]; or nuclear transfer [83-85]. The pluripotent nature of the resultant cells makes them a formidable tool for (1) studying embryonic development [86], (2) producing genetically modified animals $[87,88]$, (3) establishment of in vitro models of genetic diseases [89], and (4) developing 


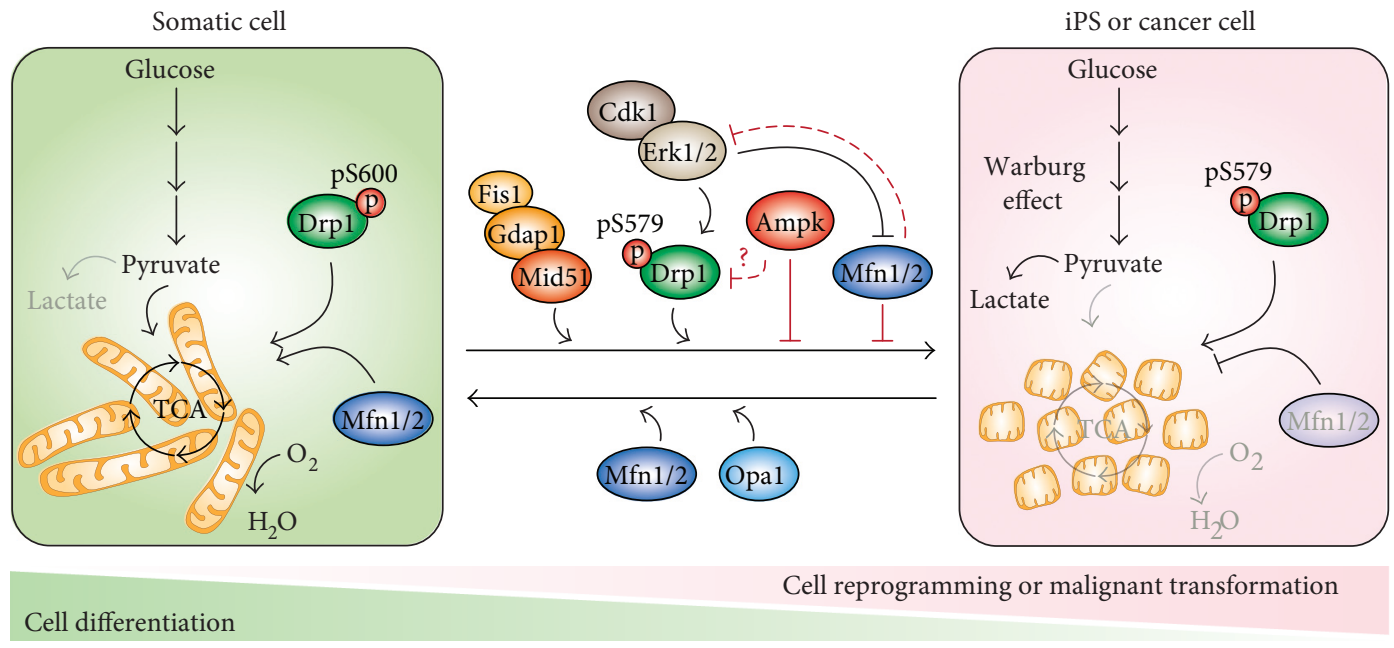

Figure 2: Mitochondrial dynamics in somatic, pluripotent, and cancer cells. Model illustrating the factors involved in the regulation of mitochondrial dynamics and metabolism in somatic, pluripotent (iPS), or cancer cells. The roles played by the indicated factors in favoring (forward arrow) or impairing (reverse arrow) cell reprogramming are also shown.

new therapies in regenerative medicine [90]. Among the different approaches, OSKM-induced somatic cell reprogramming has become the most widespread technique due to its high reproducibility, applicability to human samples, and simplicity of the process.

OSKM-induced cell reprogramming constitutes an organized sequence of events that starts with the downregulation of somatic cell markers [91]. Then, activation of cell proliferation [92], induction of a metabolic switch from OXPHOS to glycolysis [65], and a mesenchymal-to-epithelial transition (MET) $[93,94]$ follow. Finally, the process culminates with cellular immortalization [95-100] and upregulation of core pluripotency markers, such Oct4 or Nanog [91, 101]. Also, there is a global erasure of the somatic epigenetic signature during the reprogramming process, which is undertaken by histone-modifying [102-104] and DNA-modifying [105] enzymes. It has been shown that this erasure of the somatic epigenetic marks is increased sequentially cycle after cycle during cell proliferation due to a dilution effect upon cell division $[92,106,107]$.

Three seminal studies have demonstrated that the changes undertaken by somatic cells during OSKM-induced cell reprogramming are organized in two consecutive waves [108-110]. The first wave, called stochastic phase, is associated with changes in cell cycle, DNA replication, and MET. The second wave, named deterministic phase, is associated with the total reactivation of the transcriptional core of pluripotency. These studies have revealed that the low efficiency of the process is due to the fact that some of the starting somatic cells are refractory to cell reprogramming and remain trapped as cell intermediates.

In contrast to cell differentiation during embryogenesis, it has been suggested that mitochondrial dynamics follows a reverse pathway during cell reprogramming: mitochondria rejuvenate and become fragmented $[64,111]$, their functionality as energy-producing organelles is reduced $[65,112]$, and mtDNA replication is decreased [113]. Although it has been suggested that Drp1 does not play a role during
OSKM-induced somatic cell reprogramming [114], several reports indicate that this protein plays a key role in this process $[78,115,116]$. In this regard, we have observed an increase in both Drp1 total protein and Drp1-S579 phosphorylation during the stochastic phase of cell reprogramming. During early reprogramming, Erk1 and Erk2 are activated as a consequence of the downregulation of the Dusp6 protein phosphatase. Activated Erk1/2 phosphorylate Drp1-S579, which induces its recruitment to mitochondria and triggers mitochondrial fission during the stochastic phase of cell reprogramming [78] (Figure 2). In addition to Erk1/2, cyclin-dependent kinase 1 (Cdk1) could also participate in the phosphorylation of Drp1-S579 during early cell reprogramming [9]. In fact, it has been observed that the transcriptional factor associated to pluripotency reduced expression protein 1 (REX1) activates cyclin $B$ expression in human ES cells. This upregulation activates CDK1/cyclin B complex, leading to an increase in Drp1-S579 phosphorylation and mitochondrial fragmentation. REX1-null ES cells show tubular mitochondrial morphology and a decreased self-renewal capacity [116]. Also, pluripotent mouse ES cells lacking a functional Drp1 gene have been derived by homologous recombination [117] (Figure 2). Although Drp1 knockout mice show major defects in embryonic development and synapsis formation, Drp1-null ES cells maintain pluripotency and self-renewal capacities. Drp1 knockout cells display a tubular mitochondrial morphology and a lower proliferation rate. Surprisingly, lack of Drp1 gene does not affect cytokinesis. Given the central role played by Drp1 in mitochondrial fission and that this process is critical to assure an equal distribution of these organelles between the two daughter cells in each cell division, the results obtained by Ishihara and colleagues were puzzling. To circumvent this conundrum, Ishihara and colleagues suggested that unknown mechanical forces could play a role in the uneven segregation of mitochondria between the two daughter cells during cell division. 
Conversely to the conventional idea of mitochondrial fission as a mechanism for assuring the equal distribution of mitochondria between the two daughter cells during cytokinesis, a recent report showing that mitochondrial fission also drives the asymmetrical distribution of these organelles during cell division of stem-like cells adds an additional layer of complexity to the physiological roles already ascribed to the fragmentation of these organelles. Interestingly, this asymmetrical distribution of mitochondria depends on the quality of the organelles and whereas aged or deficient organelles are segregated to the more differentiated daughter cell, healthy mitochondria are retained by the resultant stem-like cell upon cytokinesis [118]. Interestingly, this asymmetric segregation of mitochondria contributes to maintain a homogenous and healthy population of stem-like cells, which could be considered as a sort of selfish selfrenewal. It would be interesting to investigate whether this unequal segregation of mitochondria takes places under normal and/or pathological conditions in vivo.

Compared to somatic cells, ES cells show low levels of $M f n 1 / 2$ expression [78, 119]. Interestingly, $M f n 1 / 2$ knockout cells display a faster and higher efficiency of cell reprogramming due to an increase of mitochondrial fragmentation and cell proliferation. Also lack of $M f n 1 / 2$ favors Erk1/2 activation, which may improve Drp1-S579 phosphorylation by these MAP-kinases [119]. Furthermore, Erk1/2-mediated phosphorylation of Mfn1 causes its inactivation [37]. Thus, in addition to increase mitochondrial fission through Drp1 phosphorylation [78], Erk1/2 activation during early cell reprogramming may inhibit mitochondrial fusion through Mfn1 phosphorylation (Figure 2).

Recently, it has been described that other proteins involved in mitochondrial fission, such as Mid51 or Gdap1, are also important for cell reprogramming [120]. Downregulation of any of these two proteins reduces cell reprogramming efficiency. Interestingly, Gdap1 knockout cells displayed a lower reprogramming efficiency due to a defect in triggering mitochondrial fragmentation during the process. The failure to undergo an efficient mitochondrial fission by Gdap1-null cells during cell reprogramming induced a DNA damageindependent G2/M arrest (Figure 2).

Important similarities between cell reprogramming and cellular transformation do exist [105]. In this regard, a similar role for mitochondrial fission in tumorigenesis has been proposed [121]. As it happens during cell reprogramming, some cellular transformation processes are associated with MET [122] and changes in mitochondrial morphology: from a tubular network to fragmented and isolated mitochondria. As observed in ES cells, lung [123], gastric [124], breast [125, 126], glioblastoma [127], colorectal [128], neuroblastoma [129], ovarian [130], pancreatic [46], and melanoma [47] cancer cells display high levels of Drp1 and low amounts of $M f n 1 / 2$ gene expression. Accordingly, inhibition of Drp1 expression or overexpression of $M f n 1 / 2$ results in a marked reduction of cancer cell proliferation and an increase in spontaneous apoptosis [123-126, 128]. Some other cancer cells are characterized by either a decrease or an increase in $M f n 1 / 2$ and Fis 1 expression levels, respectively [131, 132] (Figure 2).
Furthermore, Drp1 regulation during cellular transformation seems to be similar to that of cell reprogramming. Erk1/2 inhibition in transformed cells decreases Drp1-S579 phosphorylation levels, elongates mitochondria, and reduces cell proliferation and the capability of tumor formation $[46,47]$. In lymphoblastic leukemia cells, Erk1/2 triggers Drp1-dependent mitochondrial fission to reduce ROS and enhance glycolysis for protecting cells against chemotherapeutic agents. In this regard, activation of ERK signaling by constitutive expression of a constitutively active K-Ras mutation confers on cells a large degree of phenotypic plasticity that promotes their neoplastic transformation and the acquisition of stem cell-like characteristics [133]. Brain tumor-initiating (BTI) cells display fragmented mitochondria. BTI cells show high levels of DRP1-S579 phosphorylation and targeting DRP1 using RNA interference or pharmacologic inhibition induced apoptosis in BTI cells and inhibited tumor growth [48]. Finally, and similar to Gdap1-null cells during cell reprogramming, a knockdown of Drp1 in lung and breast cancer cells induces a DNA damage-dependent G2/M arrest [134] (Figure 2).

\section{Mitochondrial Fission and Mitophagy in Cell Reprogramming}

Mitochondrial fission is necessary for mitophagy, whereas mitochondrial fusion impairs this mitochondrial-specific form of autophagy [135]. As it has been described in a mitochondrial clearance during cell reprogramming $[111,136,137]$, some studies have suggested that mitophagy could be involved in this reduction in mitochondrial mass and therefore play a positive role in the reprogramming process $[138,139]$. Accordingly, an induction of autophagy has been shown to increase cell reprogramming efficiency [140] and an early and transitory activation of this process has been observed to take place very early in cell reprogramming to reduce mitochondrial mass [137]. However, new studies have put into question these results. Work by three different laboratories demonstrated that Lc3b/Atg5-dependent autophagy is not responsible for the mitochondrial clearance observed during cell reprogramming [78, 141, 142]. Furthermore, observations by two additional laboratories showed that ES cells have a mitochondrial mass/total protein ratio similar to that of somatic cells $[143,144]$. Thus, it seems improbable that an active reduction of mitochondrial mass by mitophagy is taking place during the cell reprogramming process. Altogether, these observations suggest that, beyond its role in the constant turnover of dysfunctional mitochondria, mitophagy seems not necessary for cell reprogramming. It is nonetheless possible that the absolute reduction of mitochondrial mass could be due to an adaptive process to the new culture conditions required to maintain pluripotency [78] or through a Lc3b/Atg5-independent autophagic pathway [141]. Paradoxically, the hypothesis of a passive mitochondrial clearance during successive rounds of cell division would require the generation of new mitochondria to maintain a proper distribution of these organelles between the two daughter cells. In keeping with this idea, it has been reported that mitochondrial biogenesis markers are induced during cell 
reprogramming $[78,111]$. The role of autophagy, in general, and mitophagy, in particular, in the maintenance of pluripotency is poorly understood; however, some studies point that autophagy activation is more important during cell differentiation than during the acquisition of the pluripotent state [145]. Further, chemical activation of Ampk reduced cell reprogramming efficiency [146], and induction of autophagy is associated with an increase in Ampk activation [147]. Interestingly, it has been described that Ampk phosphorylates Drp1-S600, which impairs Drp1 function and mitochondrial fission [55, 148, 149]. Proteomic analysis of Drp1 in mouse ES cells revealed the absence of this posttranslational modification in both mitochondrial and cytosolic fractions of the protein under self-renewal culture conditions [78]. Although it has not been described a role for this phosphorylation in cell reprogramming, it may be similar to that found in cancer cells, where dephosphorylation of Drp1-S600 has been associated to tumor progression [48]. In agreement with this, Ampk activation seems to inhibit cancer progression [150-152]. Further research may shed light into the role of Ampkmediated Drp1-S600 phosphorylation during the early stages of cell reprogramming (Figure 2).

\section{Conclusions}

In addition to changes in mitochondrial morphology, cell reprogramming induces a metabolic switch: from an oxidative-somatic state to a glycolytic-pluripotent state [153]. This metabolic remodeling presents several similarities with the Warburg effect observed in cancer cells [154]. In fact, there are many processes in which an increase of mitochondrial fission goes along with an activation of glycolysis and a decrease of OXPHOS [155]. The observed changes in both mitochondrial morphology and metabolism seem to be key for cell reprogramming and during the early events of tumorigenesis. Altogether, published data suggest a close parallelism between the stochastic phase of cell reprogramming and cellular transformation [105]. The similarities between both processes reveal that any advance in the control of induced pluripotency will not only help to manage properly this powerful tool for its biomedical application but also to better understand the early events that take place during the development of human malignancies. Interestingly, in vivo cell reprogramming is emerging as an alternative approach to regenerative medicine that does not require cell transplantation [156-159]. Given the importance of mitochondrial dynamics for somatic cell differentiation and dedifferentiation, this mitochondrial process is likely to play a key role in cell fate remodeling during in vivo cell reprogramming. It is therefore possible that the discovery of new techniques to locally modulate mitochondrial dynamics in a specific set of cells, combined with partial in vivo cell reprogramming, will set the grounds for developing novel mitochondria-based therapeutic approaches to improve human welfare.

\section{Conflicts of Interest}

The authors declare that there are no conflicts of interest.

\section{Acknowledgments}

This work was supported by Grant BFU2015-68366-R MINECO/FEDER, UE to Josema Torres. Javier Prieto was supported by a Vali+d predoctoral fellowship from Generalitat Valenciana. Josema Torres holds a Post-RyC tenure-track research award from the University of Valencia.

\section{References}

[1] M. R. Lewis and W. H. Lewis, "Mitochondria in tissue culture," Science, vol. 39, no. 1000, pp. 330-333, 1914.

[2] J. Jacobson and M. R. Duchen, "Interplay between mitochondria and cellular calcium signalling," Molecular and Cellular Biochemistry, vol. 256, no. 1, pp. 209-218, 2004.

[3] O. Stehling, C. Wilbrecht, and R. Lill, "Mitochondrial ironsulfur protein biogenesis and human disease," Biochimie, vol. 100, pp. 61-77, 2014.

[4] S. W. Tait and D. R. Green, "Mitochondria and cell death: outer membrane permeabilization and beyond," Nature Reviews. Molecular Cell Biology, vol. 11, no. 9, pp. 621-632, 2010.

[5] S. M. Cloonan and A. M. Choi, "Mitochondria: sensors and mediators of innate immune receptor signaling," Current Opinion in Microbiology, vol. 13, no. 3, pp. 327-338, 2013.

[6] D. C. Chan, "Fusion and fission: interlinked processes critical for mitochondrial health," Annual Review of Genetics, vol. 46, pp. 265-287, 2012.

[7] H. Otera, N. Ishihara, and K. Mihara, "New insights into the function and regulation of mitochondrial fission," Biochimica et Biophysica Acta, vol. 1833, no. 5, pp. 1256-1268, 2013.

[8] E. Smirnova, L. Griparic, D. L. Shurland, and A. M. van der Bliek, "Dynamin- related protein Drp1 is required for mitochondrial division in mammalian cells," Molecular Biology of the Cell, vol. 12, no. 8, pp. 2245-2256, 2001.

[9] N. Taguchi, N. Ishihara, A. Jofuku, T. Oka, and K. Mihara, "Mitotic phosphorylation of dynamin-related GTPase Drp1 participates in mitochondrial fission," The Journal of Biological Chemistry, vol. 282, no. 15, pp. 11521-11529, 2007.

[10] P. J. Hollenbeck and W. M. Saxton, "The axonal transport of mitochondria," The Journal of Cell Science, vol. 118, no. 23, pp. 5411-5419, 2005.

[11] D. Arnoult, "Mitochondrial fragmentation in apoptosis," Trends in Cell Biology, vol. 17, no. 1, pp. 6-12, 2007.

[12] H. Otera, N. Miyata, O. Kuge, and K. Mihara, "Drp1dependent mitochondrial fission via MiD49/51 is essential for apoptotic cristae remodeling," Journal of Cell Biology, vol. 212, no. 5, pp. 531-544, 2016.

[13] G. Twig, A. Elorza, A. J. Molina et al., "Fission and selective fusion govern mitochondrial segregation and elimination by autophagy," The EMBO Journal, vol. 27, no. 2, pp. 433-446, 2008.

[14] K. Mitra, C. Wunder, B. Roysam, G. Lin, and J. LippincottSchwartz, "A hyperfused mitochondrial state achieved at G1-S regulates cyclin E buildup and entry into S phase," Proceedings of the National Academy of Sciences of the United States of America, vol. 106, no. 29, pp. 1196011965, 2009.

[15] L. C. Gomes, G. Di Benedetto, and L. Scorrano, "During autophagy mitochondria elongate, are spared from degradation and sustain cell viability," Nature Cell Biology, vol. 13, no. 5, pp. 589-598, 2011. 
[16] A. S. Rambold, B. Kostelecky, N. Elia, and J. LippincottSchwartz, "Tubular network formation protects mitochondria from autophagosomal degradation during nutrient starvation," Proceedings of the National Academy of Sciences of the United States of America, vol. 198, no. 25, pp. 1019010195, 2011.

[17] H. Chen, A. Chomyn, and D. C. Chan, "Disruption of fusion results in mitochondrial heterogeneity and dysfunction," The Journal of Biological Chemistry, vol. 280, no. 28, pp. 26185-26192, 2005.

[18] S. A. Detmer and D. C. Chan, "Functions and dysfunctions of mitochondrial dynamics," Nature Reviews Molecular Cell Biology, vol. 8, no. 11, pp. 870-879, 2007.

[19] H. Chen, S. A. Detmer, A. J. Ewald, E. E. Griffin, S. E. Fraser, and D. C. Chan, "Mitofusins Mfn1 and Mfn2 coordinately regulate mitochondrial fusion and are essential for embryonic development," The Journal of Cell Biology, vol. 160, no. 2, pp. 189-200, 2003.

[20] H. Chen, J. M. McCaffery, and D. C. Chan, "Mitochondrial fusion protects against neurodegeneration in the cerebellum," Cell, vol. 130, no. 3, pp. 548-562, 2007.

[21] T. Koshiba, S. A. Detmer, J. T. Kaiser, H. Chen, J. M. McCaffery, and D. C. Chan, "Structural basis of mitochondrial tethering by mitofusin complexes," Science, vol. 305, no. 5685, pp. 858-862, 2004.

[22] S. A. Detmer and D. C. Chan, "Complementation between mouse Mfn1 and Mfn2 protects mitochondrial fusion defects caused by CMT2A disease mutations," The Journal of Cell Biology, vol. 176, no. 4, pp. 405-414, 2007.

[23] S. Hoppins and J. Nunnari, "The molecular mechanism of mitochondrial fusion," Biochimica et Biophysica Acta, vol. 1793, no. 1, pp. 20-26, 2009.

[24] O. Guillery, F. Malka, T. Landes et al., "Metalloproteasemediated OPA1 processing is modulated by the mitochondrial membrane potential," Biology of the Cell, vol. 100, no. 5, pp. 315-325, 2008.

[25] A. Olichon, L. Baricault, N. Gas et al., "Loss of OPA1 perturbates the mitochondrial inner membrane structure and integrity, leading to cytochrome c release and apoptosis," The Journal of Biological Chemistry, vol. 278, no. 10, pp. 7743-7746, 2003.

[26] D. Otsuga, B. R. Keegan, E. Brisch et al., "The dynaminrelated GTPase, Dnm1p, controls mitochondrial morphology in yeast," The Journal of Cell Biology, vol. 143, no. 2, pp. 333349, 1998.

[27] E. Smirnova, D. L. Shurland, S. N. Ryazantsev, and A. M. van der Bliek, "A human dynamin-related protein controls the distribution of mitochondria," The Journal of Cell Biology, vol. 143, no. 2, pp. 351-358, 1998.

[28] A. D. Mozdy, J. M. McCaffery, and J. M. Shaw, "Dnm1p GTPase-mediated mitochondrial fission is a multi-step process requiring the novel integral membrane component Fislp," The Journal of Cell Biology, vol. 151, no. 2, pp. 367-380, 2000.

[29] Q. Tieu and J. Nunnari, "Mdv1p is a WD repeat protein that interacts with the dynamin-related GTPase, Dnm1p, to trigger mitochondrial division," The Journal of Cell Biology, vol. 151, no. 2, pp. 353-366, 2000.

[30] A. M. van der Bliek and G. S. Payne, "Dynamin subunit interactions revealed," Developmental Cell, vol. 18, no. 5, pp. 687-688, 2010.
[31] J. A. Mears, L. L. Lackner, S. Fang, E. Ingerman, J. Nunnari, and J. E. Hinshaw, "Conformational changes in Dnm1 support a contractile mechanism for mitochondrial fission," Nature Structural and Molecular Biology, vol. 18, no. 1, pp. 20-26, 2011.

[32] H. Otera, C. Wang, M. M. Cleland et al., "Mff is an essential factor for mitochondrial recruitment of Drp1 during mitochondrial fission in mammalian cells," The Journal of Cell Biology, vol. 191, no. 6, pp. 1141-1158, 2010.

[33] C. S. Palmer, L. D. Osellame, D. Laine, O. S. Koutsopoulos, A. E. Frazier, and M. T. Ryan, "MiD49 and MiD51, new components of the mitochondrial fission machinery," EMBO Reports, vol. 12, no. 6, pp. 565-573, 2011.

[34] J. Zhao, T. Liu, S. Jin et al., "Human MIEF1 recruits Drp1 to mitochondrial outer membranes and promotes mitochondrial fusion rather than fission," The EMBO Journal, vol. 30, no. 14, pp. 2762-2778, 2011.

[35] O. C. Loson, Z. Song, H. Chen, and D. C. Chan, "Fis1, Mff, MiD49, and MiD51 mediate Drp1 recruitment in mitochondrial fission," Molecular Biology of the Cell, vol. 24, no. 5, pp. 659-666, 2013.

[36] L. D. Osellame, A. P. Singh, D. A. Stroud et al., "Cooperative and independent roles of the Drp1 adaptors Mff, MiD49 and MiD51 in mitochondrial fission," The Journal of Cell Science, vol. 129, no. 11, pp. 2170-2181, 2016.

[37] A. Pyakurel, C. Savoia, D. Hess, and L. Scorrano, "Extracellular regulated kinase phosphorylates mitofusin 1 to control mitochondrial morphology and apoptosis," Molecular Cell, vol. 58, no. 2, pp. 244-254, 2015.

[38] G. P. Leboucher, Y. C. Tsai, M. Yang et al., "Stress-induced phosphorylation and proteasomal degradation of mitofusin 2 facilitates mitochondrial fragmentation and apoptosis," Molecular Cell, vol. 47, no. 4, pp. 547-557, 2012.

[39] N. Ishihara, Y. Fujita, T. Oka, and K. Mihara, "Regulation of mitochondrial morphology through proteolytic cleavage of OPA1," The EMBO Journal, vol. 25, no. 13, pp. 2966-2977, 2006.

[40] L. Griparic, T. Kanazawa, and A. M. van der Bliek, "Regulation of the mitochondrial dynamin-like protein Opal by proteolytic cleavage," The Journal of Cell Biology, vol. 178, no. 5, pp. 757-764, 2007.

[41] Z. Song, H. Chen, M. Fiket, C. Alexander, and D. C. Chan, "OPA1 processing controls mitochondrial fusion and is regulated by mRNA splicing, membrane potential, and Yme1L," The Journal of Cell Biology, vol. 178, no. 5, pp. 749-755, 2007.

[42] B. Westermann, "Mitochondrial fusion and fission in cell life and death," The Nature Reviews Molecular Cell Biology, vol. 11, no. 12, pp. 872-784, 2010.

[43] C. Merkwirth, S. Dargazanil, T. Tatsuta et al., "Prohibitins control cell proliferation and apoptosis by regulating OPA1-dependent cristae morphogenesis in mitochondria," Genes and Development, vol. 22, no. 4, pp. 476488, 2008.

[44] D. F. Kashatus, K. H. Lim, D. C. Brady, N. L. Pershing, A. D. Cox, and C. M. Counter, "RALA and RALBP1 regulate mitochondrial fission at mitosis," Nature Cell Biology, vol. 13, no. 9, pp. 1108-1115, 2011.

[45] X. Qi, M. H. Disatnik, N. Shen, R. A. Sobel, and D. MochlyRosen, "Aberrant mitochondrial fission in neurons induced by protein kinase $\mathrm{C}\{$ delta\} under oxidative stress conditions 
in vivo," Molecular Biology of the Cell, vol. 22, no. 2, pp. 256265, 2011.

[46] J. A. Kashatus, A. Nascimento, L. J. Myers et al., "Erk2 phosphorylation of Drp1 promotes mitochondrial fission and MAPK-driven tumor growth," Molecular Cell, vol. 57, no. 3, pp. 537-551, 2015.

[47] M. N. Serasinghe, S. Y. Wieder, T. T. Renault et al., "Mitochondrial division is requisite to RAS-induced transformation and targeted by oncogenic MAPK pathway inhibitors," Molecular Cell, vol. 57, no. 3, pp. 521-536, 2015.

[48] Q. Xie, Q. Wu, C. M. Horbinski et al., "Mitochondrial control by DRP1 in brain tumor initiating cells," Nature Neuroscience, vol. 18, no. 4, pp. 501-510, 2015.

[49] C. H. Chou, C. C. Lin, M. C. Yang et al., "GSK3beta-mediated Drp1 phosphorylation induced elongated mitochondrial morphology against oxidative stress," PloS One, vol. 7, no. 11, article e49112, 2012.

[50] X. J. Han, Y. F. Lu, S. A. Li et al., "CaM kinase I alphainduced phosphorylation of Drp1 regulates mitochondrial morphology," The Journal of Cell Biology, vol. 182, no. 3, pp. 573-585, 2008.

[51] W. Wang, Y. Wang, J. Long et al., "Mitochondrial fission triggered by hyperglycemia is mediated by ROCK1 activation in podocytes and endothelial cells," Cell Metabolism, vol. 15, no. 2, pp. 186-200, 2012.

[52] C. R. Chang and C. Blackstone, "Cyclic AMP-dependent protein kinase phosphorylation of Drp1 regulates its GTPase activity and mitochondrial morphology," The Journal of Biological Chemistry, vol. 282, no. 30, pp. 21583-21587, 2007.

[53] J. T. Cribbs and S. Strack, "Reversible phosphorylation of Drp1 by cyclic AMP-dependent protein kinase and calcineurin regulates mitochondrial fission and cell death," EMBO Reports, vol. 8, no. 10, pp. 939-944, 2007.

[54] G. M. Cereghetti, A. Stangherlin, O. Martins de Brito et al., "Dephosphorylation by calcineurin regulates translocation of Drp1 to mitochondria," Proceedings of the National Academy of Sciences of the United States of America, vol. 105, no. 41, pp. 15803-15808, 2008.

[55] J. D. Wikstrom, T. Israeli, E. Bachar-Wikstrom et al., "AMPK regulates ER morphology and function in stressed pancreatic beta-cells via phosphorylation of DRP1," Molecular Endocrinology, vol. 27, no. 10, pp. 1706-1723, 2013.

[56] E. Q. Toyama, S. Herzig, J. Courchet et al., "Metabolism. AMP-activated protein kinase mediates mitochondrial fission in response to energy stress," Science, vol. 351, no. 6270, pp. 275-281, 2016.

[57] J. R. Friedman, L. L. Lackner, M. West, J. R. DiBenedetto, J. Nunnari, and G. K. Voeltz, "ER tubules mark sites of mitochondrial division," Science, vol. 334, no. 6054, pp. 358-362, 2011.

[58] F. Korobova, V. Ramabhadran, and H. N. Higgs, "An actindependent step in mitochondrial fission mediated by the ER-associated formin INF2," Science, vol. 339, no. 6118, pp. 464-467, 2013.

[59] A. Niemann, M. Ruegg, V. La Padula, A. Schenone, and U. Suter, "Ganglioside-induced differentiation associated protein 1 is a regulator of the mitochondrial network: new implications for Charcot-Marie-Tooth disease," The Journal of Cell Biology, vol. 170, no. 7, pp. 1067-1078, 2005.

[60] D. Pla-Martin, C. B. Rueda, A. Estela et al., "Silencing of the Charcot-Marie-Tooth disease-associated gene GDAP1 induces abnormal mitochondrial distribution and affects $\mathrm{Ca} 2+$ homeostasis by reducing store-operated $\mathrm{Ca} 2+$ entry," Neurobiology of Disease, vol. 55, pp. 140-151, 2013.

[61] V. Lopez Del Amo, M. Seco-Cervera, J. L. Garcia-Gimenez, A. J. Whitworth, F. V. Pallardo, and M. I. Galindo, "Mitochondrial defects and neuromuscular degeneration caused by altered expression of Drosophila Gdap1: implications for the Charcot-Marie-Tooth neuropathy," Human Molecular Genetics, vol. 24, no. 1, pp. 21-36, 2015.

[62] J. Van Blerkom, "Mitochondria in early mammalian development," Seminars in Cell and Developmental Biology, vol. 20, no. 3, pp. 354-364, 2009.

[63] J. C. S. John, J. Ramalho-Santos, H. L. Gray et al., "The expression of mitochondrial DNA transcription factors during early cardiomyocyte in vitro differentiation from human embryonic stem cells," Cloning and Stem Cells, vol. 7, no. 3, pp. 141-153, 2005.

[64] S. T. Suhr, E. A. Chang, J. Tjong et al., "Mitochondrial rejuvenation after induced pluripotency," PloS One, vol. 5, no. 11, article e14095, 2010.

[65] C. D. Folmes, T. J. Nelson, A. Martinez-Fernandez et al., "Somatic oxidative bioenergetics transitions into pluripotencydependent glycolysis to facilitate nuclear reprogramming," Cell Metabolism, vol. 14, no. 2, pp. 264-271, 2011.

[66] A. Prigione, B. Lichtner, H. Kuhl et al., "Human induced pluripotent stem cells harbor homoplasmic and heteroplasmic mitochondrial DNA mutations while maintaining human embryonic stem cell-like metabolic reprogramming," Stem Cells, vol. 29, no. 9, pp. 1338-1348, 2011.

[67] Y. M. Cho, S. Kwon, Y. K. Pak et al., "Dynamic changes in mitochondrial biogenesis and antioxidant enzymes during the spontaneous differentiation of human embryonic stem cells," Biochemical and Biophysical Research Communications, vol. 348, no. 4, pp. 1472-1478, 2006.

[68] J. M. Facucho-Oliveira, J. Alderson, E. C. Spikings, S. Egginton, and J. C. S. John, "Mitochondrial DNA replication during differentiation of murine embryonic stem cells," The Journal of Cell Science, vol. 120, no. 22, pp. 4025-4034, 2007.

[69] E. C. Spikings, J. Alderson, and J. C. S. John, "Regulated mitochondrial DNA replication during oocyte maturation is essential for successful porcine embryonic development," Biology of Reproduction, vol. 76, no. 2, pp. 327-335, 2007.

[70] S. Chung, P. P. Dzeja, R. S. Faustino, C. Perez-Terzic, A. Behfar, and A. Terzic, "Mitochondrial oxidative metabolism is required for the cardiac differentiation of stem cells," Nature Clinical Practice. Cardiovascular Medicine, vol. 4, no. 1, pp. S60-S67, 2007.

[71] J. R. Hom, R. A. Quintanilla, D. L. Hoffman et al., "The permeability transition pore controls cardiac mitochondrial maturation and myocyte differentiation," Developmental Cell, vol. 21, no. 3, pp. 469-478, 2011.

[72] K. V. Tormos, E. Anso, R. B. Hamanaka et al., "Mitochondrial complex III ROS regulate adipocyte differentiation," Cell Metabolism, vol. 14, no. 4, pp. 537-544, 2011.

[73] A. Kasahara, S. Cipolat, Y. Chen, G. W. Dorn 2nd, and L. Scorrano, "Mitochondrial fusion directs cardiomyocyte differentiation via calcineurin and notch signaling," Science, vol. 342, no. 6159, pp. 734-737, 2013.

[74] K. H. Flippo and S. Strack, "Mitochondrial dynamics in neuronal injury, development and plasticity," Journal of Cell Science, vol. 130, no. 4, pp. 671-681, 2017. 
[75] A. M. Bertholet, T. Delerue, A. M. Millet et al., "Mitochondrial fusion/fission dynamics in neurodegeneration and neuronal plasticity," Neurobiology of Disease, vol. 90, pp. 3-19, 2016.

[76] R. D. Kelly, A. Mahmud, M. McKenzie, I. A. Trounce, and J. C. S. John, "Mitochondrial DNA copy number is regulated in a tissue specific manner by DNA methylation of the nuclear-encoded DNA polymerase gamma A," Nucleic Acids Research, vol. 40, no. 20, pp. 10124-10138, 2012.

[77] N. G. Larsson, J. Wang, H. Wilhelmsson et al., "Mitochondrial transcription factor A is necessary for mtDNA maintenance and embryogenesis in mice," Nature Genetics, vol. 18, no. 3, pp. 231-236, 1998.

[78] J. Prieto, M. Leon, X. Ponsoda et al., "Early ERK1/2 activation promotes DRP1-dependent mitochondrial fission necessary for cell reprogramming," Nature Communications, vol. 7, article 11124, 2016.

[79] L. R. Todd, M. N. Damin, R. Gomathinayagam, S. R. Horn, A. R. Means, and U. Sankar, "Growth factor erv1-like modulates Drp1 to preserve mitochondrial dynamics and function in mouse embryonic stem cells," Molecular Biology of the Cell, vol. 21, no. 7, pp. 1225-1236, 2010.

[80] M. Khacho, A. Clark, D. S. Svoboda et al., "Mitochondrial dynamics impacts stem cell identity and fate decisions by regulating a nuclear transcriptional program," Cell Stem Cell, vol. 19, no. 2, pp. 232-247, 2016.

[81] K. Takahashi and S. Yamanaka, "Induction of pluripotent stem cells from mouse embryonic and adult fibroblast cultures by defined factors," Cell, vol. 126, no. 4, pp. 663-676, 2006.

[82] P. Hou, Y. Li, X. Zhang et al., "Pluripotent stem cells induced from mouse somatic cells by small-molecule compounds," Science, vol. 341, no. 6146, pp. 651-654, 2013.

[83] J. B. Cibelli, S. L. Stice, P. J. Golueke et al., "Transgenic bovine chimeric offspring produced from somatic cellderived stem-like cells," Nature Biotechnology, vol. 16, no. 7, pp. 642-646, 1998.

[84] M. J. Munsie, A. E. Michalska, C. M. O'Brien, A. O. Trounson, M. F. Pera, and P. S. Mountford, "Isolation of pluripotent embryonic stem cells from reprogrammed adult mouse somatic cell nuclei," Current Biology, vol. 10, no. 16, pp. 989-992, 2000.

[85] T. Wakayama, V. Tabar, I. Rodriguez, A. C. Perry, L. Studer, and P. Mombaerts, "Differentiation of embryonic stem cell lines generated from adult somatic cells by nuclear transfer," Science, vol. 292, no. 5517, pp. 740-743, 2001.

[86] F. M. Spagnoli and A. Hemmati-Brivanlou, "Guiding embryonic stem cells towards differentiation: lessons from molecular embryology," Current Opinion in Genetics and Development, vol. 16, no. 5, pp. 469-475, 2006.

[87] E. Robertson, A. Bradley, M. Kuehn, and M. Evans, "Germ-line transmission of genes introduced into cultured pluripotential cells by retroviral vector," Nature, vol. 323, no. 6087, pp. 445-448, 1986.

[88] S. Thompson, A. R. Clarke, A. M. Pow, M. L. Hooper, and D. W. Melton, "Germ line transmission and expression of a corrected HPRT gene produced by gene targeting in embryonic stem cells," Cell, vol. 56, no. 2, pp. 313-321, 1989.

[89] F. P. Di Giorgio, M. A. Carrasco, M. C. Siao, T. Maniatis, and K. Eggan, "Non-cell autonomous effect of glia on motor neurons in an embryonic stem cell-based ALS model," Nature Neuroscience, vol. 10, no. 5, pp. 608-614, 2007.
[90] G. Keller, "Embryonic stem cell differentiation: emergence of a new era in biology and medicine," Genes and Development, vol. 19, no. 10, pp. 1129-1155, 2005.

[91] M. Stadtfeld, N. Maherali, D. T. Breault, and K. Hochedlinger, "Defining molecular cornerstones during fibroblast to iPS cell reprogramming in mouse," Cell Stem Cell, vol. 2, no. 3, pp. 230-240, 2008.

[92] T. S. Mikkelsen, J. Hanna, X. Zhang et al., "Dissecting direct reprogramming through integrative genomic analysis," Nature, vol. 454, no. 7200, pp. 49-55, 2008.

[93] R. Li, J. Liang, S. Ni et al., "A mesenchymal-to-epithelial transition initiates and is required for the nuclear reprogramming of mouse fibroblasts," Cell Stem Cell, vol. 7, no. 1, pp. 51-63, 2010.

[94] P. Samavarchi-Tehrani, A. Golipour, L. David et al., "Functional genomics reveals a BMP-driven mesenchymalto-epithelial transition in the initiation of somatic cell reprogramming," Cell Stem Cell, vol. 7, no. 1, pp. 64-77, 2010.

[95] A. Banito, S. T. Rashid, J. C. Acosta et al., "Senescence impairs successful reprogramming to pluripotent stem cells," Genes and Development, vol. 23, no. 18, pp. 21342139, 2009.

[96] H. Hong, K. Takahashi, T. Ichisaka et al., "Suppression of induced pluripotent stem cell generation by the p53-p21 pathway," Nature, vol. 460, no. 7259, pp. 1132-1135, 2009.

[97] T. Kawamura, J. Suzuki, Y. V. Wang et al., "Linking the p53 tumour suppressor pathway to somatic cell reprogramming," Nature, vol. 460, no. 7259, pp. 1140-1144, 2009.

[98] H. Li, M. Collado, A. Villasante et al., “The Ink4/Arf locus is a barrier for iPS cell reprogramming," Nature, vol. 460, no. 7259, pp. 1136-1139, 2009.

[99] R. M. Marion, K. Strati, H. Li et al., “A p53-mediated DNA damage response limits reprogramming to ensure iPS cell genomic integrity," Nature, vol. 460, no. 7259, pp. 1149$1153,2009$.

[100] J. Utikal, J. M. Polo, M. Stadtfeld et al., "Immortalization eliminates a roadblock during cellular reprogramming into iPS cells," Nature, vol. 460, no. 7259, pp. 1145-1148, 2009.

[101] T. Brambrink, R. Foreman, G. G. Welstead et al., "Sequential expression of pluripotency markers during direct reprogramming of mouse somatic cells," Cell Stem Cell, vol. 2, no. 2, pp. 151-159, 2008.

[102] Y. S. Ang, S. Y. Tsai, D. F. Lee et al., "Wdr5 mediates selfrenewal and reprogramming via the embryonic stem cell core transcriptional network," Cell, vol. 145, no. 2, pp. 183-197, 2011.

[103] T. Wang, K. Chen, X. Zeng, M. A. Esteban, G. Pan, and D. Pei, "The histone demethylases Jhdmla/lb enhance somatic cell reprogramming in a vitamin-C-dependent manner," Cell Stem Cell, vol. 9, no. 6, pp. 575-587, 2011.

[104] X. Ding, X. Wang, S. Sontag et al., "The polycomb protein Ezh2 impacts on induced pluripotent stem cell generation," Stem Cells and Development, vol. 23, no. 9, pp. 931-940, 2014.

[105] E. Apostolou and K. Hochedlinger, "Chromatin dynamics during cellular reprogramming," Nature, vol. 502, no. 7472, pp. $46-471,2013$.

[106] N. Maherali, R. Sridharan, W. Xie et al., "Directly reprogrammed fibroblasts show global epigenetic remodeling and widespread tissue contribution," Cell Stem Cell, vol. 1, no. 1, pp. 55-70, 2007. 
[107] J. M. Polo, S. Liu, M. E. Figueroa et al., "Cell type of origin influences the molecular and functional properties of mouse induced pluripotent stem cells," Nature Biotechnology, vol. 28, no. 8, pp. 848-855, 2010.

[108] Y. Buganim, D. A. Faddah, A. W. Cheng et al., "Single-cell expression analyses during cellular reprogramming reveal an early stochastic and a late hierarchic phase," Cell, vol. 150, no. 6, pp. 1209-1222, 2012.

[109] J. Hansson, M. R. Rafiee, S. Reiland et al., "Highly coordinated proteome dynamics during reprogramming of somatic cells to pluripotency," Cell Reports, vol. 2, no. 6, pp. 15791592, 2012.

[110] J. M. Polo, E. Anderssen, R. M. Walsh et al., "A molecular roadmap of reprogramming somatic cells into iPS cells," Cell, vol. 151, no. 7, pp. 1617-1632, 2012.

[111] A. Prigione and J. Adjaye, "Modulation of mitochondrial biogenesis and bioenergetic metabolism upon in vitro and in vivo differentiation of human ES and iPS cells," The International Journal of Developmental Biology, vol. 54, no. 11-12, pp. 1729-1741, 2010.

[112] H. W. Choi, J. H. Kim, M. K. Chung et al., "Mitochondrial and metabolic remodeling during reprogramming and differentiation of the reprogrammed cells," Stem Cells and Development, vol. 24, no. 11, pp. 1366-1373, 2015.

[113] R. D. Kelly, H. Sumer, M. McKenzie et al., "The effects of nuclear reprogramming on mitochondrial DNA replication," Stem Cell Reviews and Reports, vol. 9, no. 1, pp. 115, 2013.

[114] L. Wang, X. Ye, Q. Zhao et al., "Drp1 is dispensable for mitochondria biogenesis in induction to pluripotency but required for differentiation of embryonic stem cells," Stem Cells and Development, vol. 23, no. 20, pp. 2422-2434, 2014.

[115] A. Vazquez-Martin, S. Cufi, B. Corominas-Faja, C. OliverasFerraros, L. Vellon, and J. A. Menendez, "Mitochondrial fusion by pharmacological manipulation impedes somatic cell reprogramming to pluripotency: new insight into the role of mitophagy in cell stemness," Aging, vol. 4, no. 6, pp. 393-401, 2012.

[116] M. Y. Son, H. Choi, Y. M. Han, and Y. S. Cho, "Unveiling the critical role of REX1 in the regulation of human stem cell pluripotency," Stem Cells, vol. 31, no. 11, pp. 23742387, 2013.

[117] N. Ishihara, M. Nomura, A. Jofuku et al., "Mitochondrial fission factor Drp1 is essential for embryonic development and synapse formation in mice," Nature Cell Biology, vol. 11, no. 8, pp. 958-966, 2009.

[118] P. Katajisto, J. Dohla, C. L. Chaffer et al., "Stem cells. Asymmetric apportioning of aged mitochondria between daughter cells is required for stemness," Science, vol. 348, no. 6232, pp. 340-343, 2015.

[119] M. J. Son, Y. Kwon, M. Y. Son et al., "Mitofusins deficiency elicits mitochondrial metabolic reprogramming to pluripotency," Cell Death and Differentiation, vol. 22, no. 12, pp. 1957-1969, 2015.

[120] J. Prieto, M. Leon, X. Ponsoda et al., "Dysfunctional mitochondrial fission impairs cell reprogramming," Cell Cycle, vol. 15, no. 23, pp. 3240-3250, 2016.

[121] M. L. Boland, A. H. Chourasia, and K. F. Macleod, "Mitochondrial dysfunction in cancer," Frontiers in Oncology, vol. 3, p. 292, 2013.
[122] B. De Craene and G. Berx, "Regulatory networks defining EMT during cancer initiation and progression," Nature Reviews Cancer, vol. 13, no. 2, pp. 97-110, 2013.

[123] J. Rehman, H. J. Zhang, P. T. Toth et al., "Inhibition of mitochondrial fission prevents cell cycle progression in lung cancer," The FASEB Journal, vol. 26, no. 5, pp. 2175-2186, 2012.

[124] G. E. Zhang, H. L. Jin, X. K. Lin et al., "Anti-tumor effects of Mfn2 in gastric cancer," International Journal of Molecular Sciences, vol. 14, no. 7, pp. 13005-13021, 2013.

[125] L. Ma, Y. Liu, C. Geng, X. Qi, and J. Jiang, "Estrogen receptor beta inhibits estradiol-induced proliferation and migration of MCF-7 cells through regulation of mitofusin 2," International Journal of Oncology, vol. 42, no. 6, pp. 1993-2000, 2013.

[126] J. Zhao, J. Zhang, M. Yu et al., "Mitochondrial dynamics regulates migration and invasion of breast cancer cells," Oncogene, vol. 32, no. 40, pp. 4814-4824, 2013.

[127] Y. Y. Wan, J. F. Zhang, Z. J. Yang et al., "Involvement of Drp1 in hypoxia-induced migration of human glioblastoma U251 cells," Oncology Reports, vol. 32, no. 2, pp. 619-626, 2014.

[128] A. Inoue-Yamauchi and H. Oda, "Depletion of mitochondrial fission factor DRP1 causes increased apoptosis in human colon cancer cells," Biochemical and Biophysical Research Communications, vol. 421, no. 1, pp. 81-85, 2012.

[129] J. Hagenbuchner, A. V. Kuznetsov, P. Obexer, and M. J. Ausserlechner, "BIRC5/Survivin enhances aerobic glycolysis and drug resistance by altered regulation of the mitochondrial fusion/fission machinery," Oncogene, vol. 32, no. 40, pp. 4748-4757, 2013.

[130] D. K. Tanwar, D. J. Parker, P. Gupta et al., "Crosstalk between the mitochondrial fission protein, Drp1, and the cell cycle is identified across various cancer types and can impact survival of epithelial ovarian cancer patients," Oncotarget, vol. 7, no. 37, pp. 60021-60037, 2016.

[131] D. M. Su, Q. Zhang, X. Wang et al., “Two types of human malignant melanoma cell lines revealed by expression patterns of mitochondrial and survival-apoptosis genes: implications for malignant melanoma therapy," Molecular Cancer Therapeutics, vol. 8, no. 5, pp. 1292-1304, 2009.

[132] J. P. White, K. A. Baltgalvis, M. J. Puppa, S. Sato, J. W. Baynes, and J. A. Carson, "Muscle oxidative capacity during IL-6dependent cancer cachexia," American Journal of Physiology. Regulatory, Integrative and Comparative Physiology, vol. 300, no. 2, pp. R201-R211, 2011.

[133] I. Ischenko, J. Zhi, U. M. Moll, A. Nemajerova, and O. Petrenko, "Direct reprogramming by oncogenic Ras and Myc," Proceedings of the National Academy of Sciences of the United States of America, vol. 110, no. 10, pp.3937-3942, 2013.

[134] W. Qian, S. Choi, G. A. Gibson, S. C. Watkins, C. J. Bakkenist, and B. Van Houten, "Mitochondrial hyperfusion induced by loss of the fission protein Drp1 causes ATMdependent G2/M arrest and aneuploidy through DNA replication stress," The Journal of Cell Science, vol. 125, no. 23, pp. 5745-5757, 2012.

[135] G. Ashrafi and T. L. Schwarz, "The pathways of mitophagy for quality control and clearance of mitochondria," Cell Death and Differentiation, vol. 20, no. 1, pp. 31-42, 2013.

[136] A. Prigione, B. Fauler, R. Lurz, H. Lehrach, and J. Adjaye, "The senescence- related mitochondrial/oxidative stress pathway is repressed in human induced pluripotent stem cells," Stem Cells, vol. 28, no. 4, pp. 721-733, 2010. 
[137] S. Wang, P. Xia, B. Ye, G. Huang, J. Liu, and Z. Fan, "Transient activation of autophagy via Sox2-mediated suppression of mTOR is an important early step in reprogramming to pluripotency," Cell Stem Cell, vol. 13, no. 5, pp. 617-625, 2013.

[138] A. T. Vessoni, A. R. Muotri, and O. K. Okamoto, "Autophagy in stem cell maintenance and differentiation," Stem Cells and Development, vol. 21, no. 4, pp. 513-520, 2012.

[139] H. Pan, N. Cai, M. Li, G. H. Liu, and J. C. Izpisua Belmonte, "Autophagic control of cell 'stemness'," EMBO Molecular Medicine, vol. 5, no. 3, pp. 327-331, 2013.

[140] T. Chen, L. Shen, J. Yu et al., "Rapamycin and other longevity-promoting compounds enhance the generation of mouse induced pluripotent stem cells," Aging Cell, vol. 10, no. 5, pp. 908-911, 2011.

[141] T. Ma, J. Li, Y. Xu et al., “Atg5-independent autophagy regulates mitochondrial clearance and is essential for iPSC reprogramming," Nature Cell Biology, vol. 17, no. 11, pp. 1379-1387, 2015.

[142] Y. Wu, Y. Li, and H. Zhang, "Autophagy and mTORC1 regulate the stochastic phase of somatic cell reprogramming," Nature Cell Biology, vol. 17, no. 6, pp. 715-725, 2015.

[143] M. J. Birket, A. L. Orr, A. A. Gerencser et al., "A reduction in ATP demand and mitochondrial activity with neural differentiation of human embryonic stem cells," The Journal of Cell Science, vol. 124, no. 3, pp. 348-358, 2011.

[144] J. Zhang, I. Khvorostov, J. S. Hong et al., "UCP2 regulates energy metabolism and differentiation potential of human pluripotent stem cells," The EMBO Journal, vol. 30 , no. 24, pp. 4860-4873, 2011.

[145] J. L. Guan, A. K. Simon, M. Prescott et al., "Autophagy in stem cells," Autophagy, vol. 9, no. 6, pp. 830-849, 2013.

[146] A. Vazquez-Martin, L. Vellon, P. M. Quiros et al., "Activation of AMP-activated protein kinase (AMPK) provides a metabolic barrier to reprogramming somatic cells into stem cells," Cell Cycle, vol. 11, no. 5, pp. 974-989, 2012.

[147] D. G. Hardie, "AMPK and autophagy get connected," The EMBO Journal, vol. 30, no. 4, pp. 634-635, 2011.

[148] J. Li, Y. Wang, Y. Wang et al., "Pharmacological activation of AMPK prevents Drp1-mediated mitochondrial fission and alleviates endoplasmic reticulum stress-associated endothelial dysfunction," Journal of Molecular and Cellular Cardiology, vol. 86, pp. 62-74, 2015.

[149] A. Li, S. Zhang, J. Li, K. Liu, F. Huang, and B. Liu, "Metformin and resveratrol inhibit Drp1-mediated mitochondrial fission and prevent ER stress-associated NLRP3 inflammasome activation in the adipose tissue of diabetic mice," Molecular and Cellular Endocrinology, vol. 434, pp. 36-47, 2016.

[150] K. N. Phoenix, C. V. Devarakonda, M. M. Fox, L. E. Stevens, and K. P. Claffey, "AMPKalpha2 suppresses murine embryonic fibroblast transformation and tumorigenesis," Genes \& Cancer, vol. 3, no. 1, pp. 51-62, 2012.

[151] A. Sato, J. Sunayama, M. Okada et al., "Glioma-initiating cell elimination by metformin activation of FOXO3 via AMPK," Stem Cells Translational Medicine, vol. 1, no. 11, pp. 811-824, 2012.

[152] C. T. Pineda, S. Ramanathan, K. Fon Tacer et al., "Degradation of AMPK by a cancer-specific ubiquitin ligase," Cell, vol. 160, no. 4, pp. 715-728, 2015.
[153] J. Wu, A. Ocampo, and J. C. Izpisua Belmonte, "Cellular metabolism and induced pluripotency," Cell, vol. 166, no. 6, pp. 1371-1385, 2016.

[154] R. J. DeBerardinis, J. J. Lum, G. Hatzivassiliou, and C. B. Thompson, "The biology of cancer: metabolic reprogramming fuels cell growth and proliferation," Cell Metabolism, vol. 7, no. 1, pp. 11-20, 2008.

[155] P. Mishra and D. C. Chan, "Metabolic regulation of mitochondrial dynamics," The Journal of Cell Biology, vol. 212, no. 4, pp. 379-387, 2016.

[156] M. Abad, L. Mosteiro, C. Pantoja et al., "Reprogramming in vivo produces teratomas and iPS cells with totipotency features," Nature, vol. 502, no. 7471, pp. 340-345, 2013.

[157] D. Srivastava and N. DeWitt, "In vivo cellular reprogramming: the next generation," Cell, vol. 166, no. 6, pp. 1386-1396, 2016.

[158] L. Mosteiro, C. Pantoja, N. Alcazar et al., "Tissue damage and senescence provide critical signals for cellular reprogramming in vivo," Science, vol. 354, no. 6315, pp. aaf4445-1aaf4445-10, 2016.

[159] A. Ocampo, P. Reddy, P. Martinez-Redondo et al., "In vivo amelioration of age-associated hallmarks by partial reprogramming," Cell, vol. 167, no. 7, pp. 1719-1733, 2016, e12. 

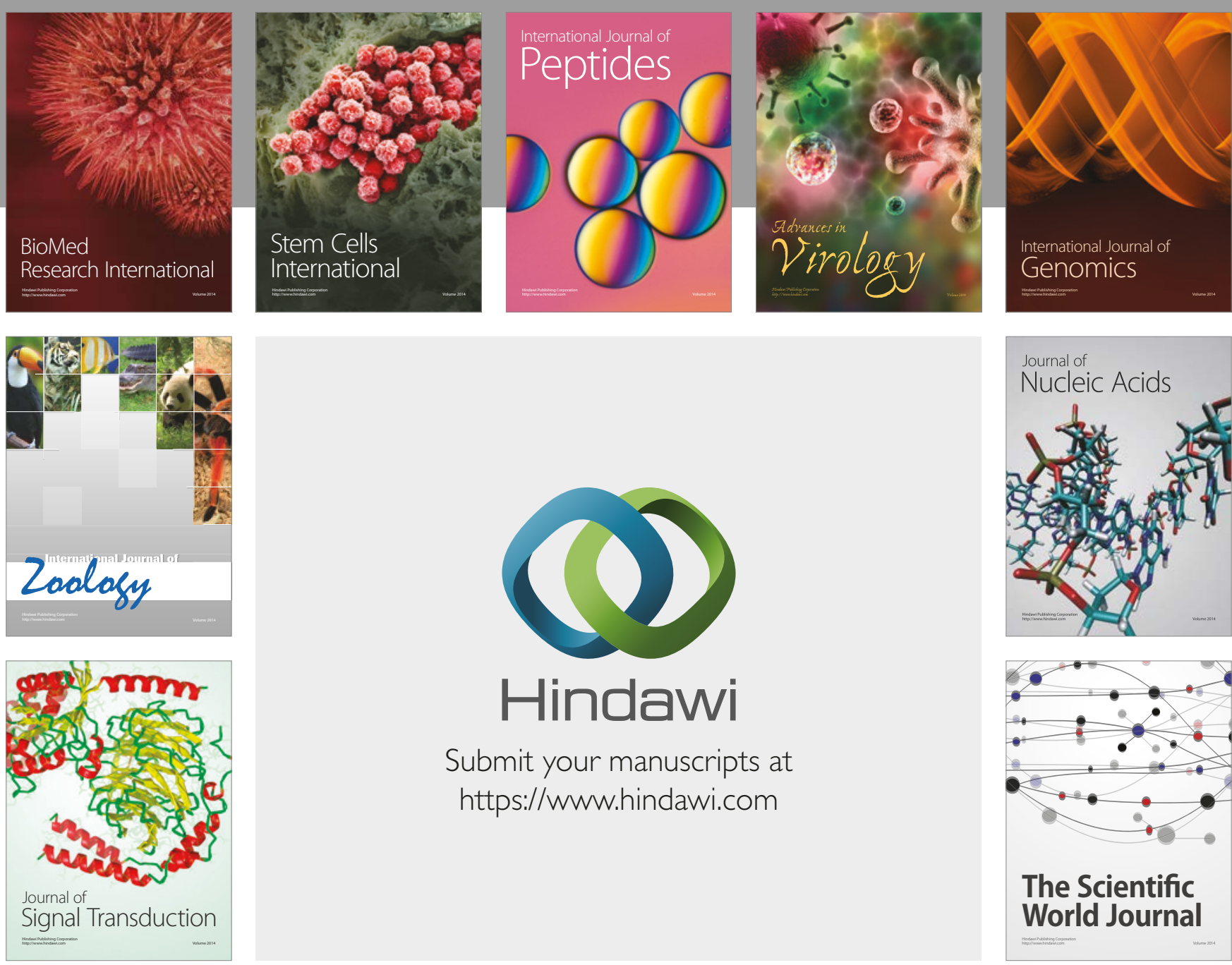

Submit your manuscripts at

https://www.hindawi.com
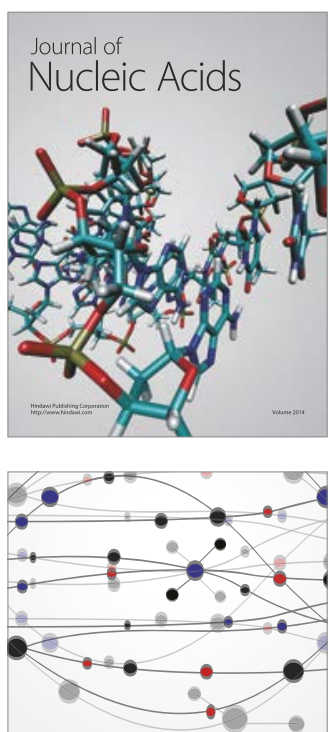

The Scientific World Journal

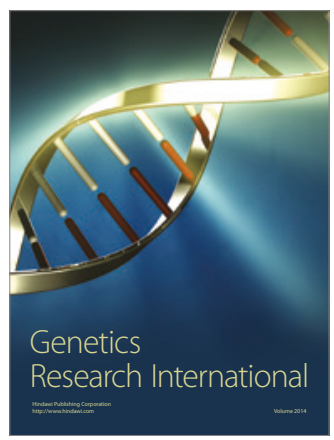

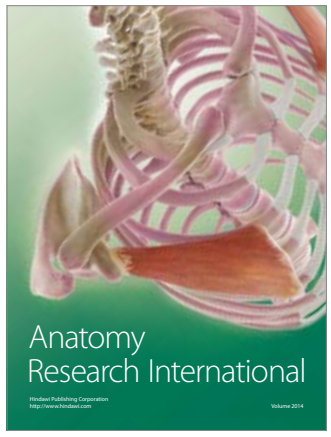

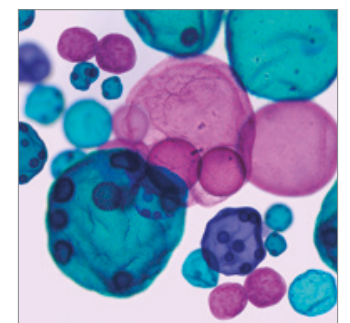

International Journal of Microbiology
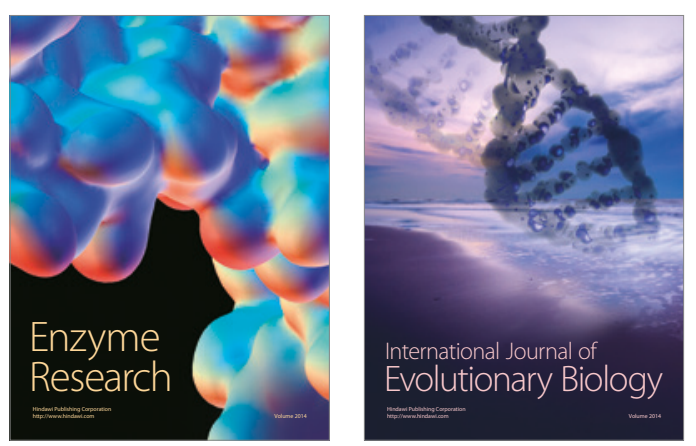
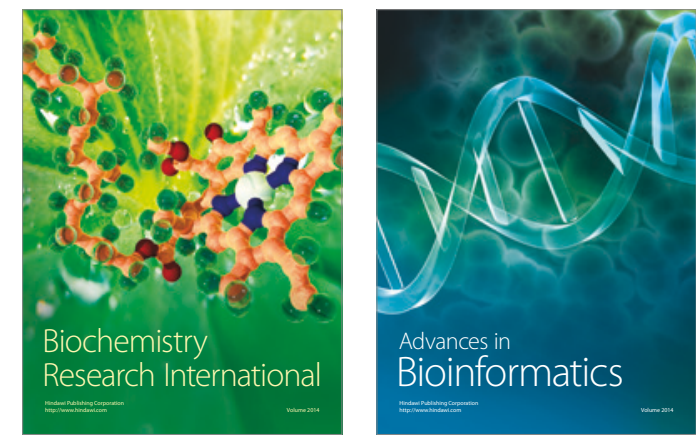

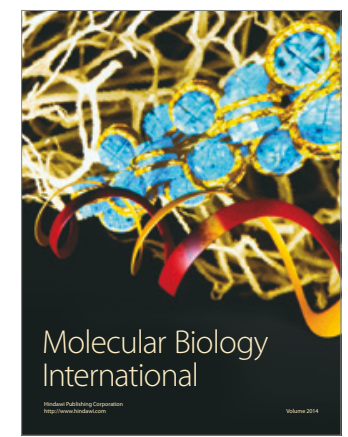

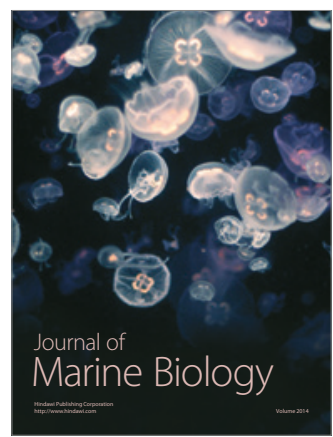

